\title{
Comprehensive study of altered proteomic landscape in proximal renal tubular epithelial cells in response to calcium oxalate monohydrate crystals
}

Zhu Wang ${ }^{1 *+}$, Ming-xing $\mathrm{Li}^{2 \dagger}$, Chang-zhi Xu ${ }^{3 \dagger}$, Ying Zhang ${ }^{1}$, Qiong Deng ${ }^{1}$, Rui Sun ${ }^{1}$, Qi-yi Hu${ }^{1}$, Sheng-ping Zhang ${ }^{1}$, Jian-wen Zhang ${ }^{1}$ and Hui Liang ${ }^{1 *}$

\begin{abstract}
Background: Calcium oxalate monohydrate (COM), the major crystalline composition of most kidney stones, induces inflammatory infiltration and injures in renal tubular cells. However, the mechanism of COM-induced toxic effects in renal tubular cells remain ambiguous. The present study aimed to investigate the potential changes in proteomic landscape of proximal renal tubular cells in response to the stimulation of COM crystals.

Methods: Clinical kidney stone samples were collected and characterized by a stone component analyzer. Three COM-enriched samples were applied to treat human proximal tubular epithelial cells HK-2. The proteomic landscape of COM-crystal treated HK-2 cells was screened by TMT-labeled quantitative proteomics analysis. The differentially expressed proteins (DEPs) were identified by pair-wise analysis. Gene Ontology (GO) analysis and Kyoto Encyclopedia of Genes and Genomes (KEGG) pathway analysis of DEPs were performed. Protein interaction networks were identified by STRING database.

Results: The data of TMT-labeled quantitative proteomic analysis showed that a total of 1141 proteins were differentially expressed in HK-2 cells, of which 699 were up-regulated and 442 were down-regulated. Functional characterization by KEGG, along with GO enrichments, suggests that the DEPs are mainly involved in cellular components and cellular processes, including regulation of actin cytoskeleton, tight junction and focal adhesion. 3 high-degree hub nodes, CFL1, ACTN and MYH9 were identified by STRING analysis.
\end{abstract}

Conclusion: These results suggested that calcium oxalate crystal has a significant effect on protein expression profile in human proximal renal tubular epithelial cells.

Keywords: Calcium oxalate crystal, Kidney stone, Protein expression profile, Renal epithelial cells

\footnotetext{
*Correspondence: wangzhu1223@hotmail.com; dr.1ianghui@aliyun.com

${ }^{\dagger}$ Zhu Wang, Ming-xing Li and Chang-zhi Xu contributed equally to this work.

'Department of Urology, People's Hospital of Longhua, Southern Medical

University, Shenzhen 518109, Guangdong, China

Full list of author information is available at the end of the article
}

(c) The Author(s). 2020 Open Access This article is licensed under a Creative Commons Attribution 4.0 International License, which permits use, sharing, adaptation, distribution and reproduction in any medium or format, as long as you give appropriate credit to the original author(s) and the source, provide a link to the Creative Commons licence, and indicate if changes were made. The images or other third party material in this article are included in the article's Creative Commons licence, unless indicated otherwise in a credit line to the material. If material is not included in the article's Creative Commons licence and your intended use is not permitted by statutory regulation or exceeds the permitted use, you will need to obtain permission directly from the copyright holder. To view a copy of this licence, visit http://creativecommons.org/licenses/by/4.0/. The Creative Commons Public Domain Dedication waiver (http://creativecommons.org/publicdomain/zero/1.0/) applies to the data made available in this article, unless otherwise stated in a credit line to the data. 


\section{Background}

Kidney stone is a common disease with prevalence and incidence increasing across the world that seriously affects human health. Generally, it can cause urinary retention, renal pelvis and ureteral hydrops, ureteral dilatation, renal function damage, and infection. The prevalence of kidney stones exhibited a significant increasing trend in the past decades in the mainland of China $[1,2]$. The latest research shows that the prevalence of Chinese adult kidney stones is $5.8 \%$, and the life-time prevalence in South China is as high as $26.6 \%$ [3]. Kidney stone disease mainly affects people aged 3050 years old, and half the patients suffered kidney stone recurrence [4]. Kidney stone seriously affects the health and quality of life of patients, and has become a public health problem across the world.

Calcium Oxalate Monohydrate (COM) accounts for over $80 \%$ of the incidence of stones [5]. COM caused renal tubular epithelial cells expressing a variety of macromolecules [6], thus affecting adhesion, aggregation and growth of calcium oxalate crystals plays an important role in the formation of kidney stones $[6,7]$. Studies reported that the COM crystal-cell interaction stimulates the expression of NADPH oxidase in renal tubular epithelial cells, triggers the massive production of reactive oxygen species, activates the nuclear factor- $\mathrm{k} B$ signal transduction pathway, and releases a large number of inflammatory factors and activates the inflammatory cascade, links to local intrarenal inflammation and kidney injury [8-11].

Recently, the mechanism of kidney stone formation has been increasingly concerned. Serval studies demonstrated that kidney stones are initiated by COM crystals deposition due to supersaturation of urinary calcium and oxalate ions [12]. These deposits may act as nidus for stone growth, adhere to apical surface of renal tubular epithelial cells via several crystal-binding molecules or potential crystal receptors [13]. Calcium oxalate stone matrix has been reported to include a large number of protein molecules, which were identified and evidenced to promote the aggregation, nucleation and growth of calcium oxalate crystals in kidney, which ultimately leads to the formation of stones [6, 7, 14-16]. CD44, OPN, MCP-1 and HA are the most widely studied proteins which calcium oxalate crystal attachment depends upon [8, 17]. However, various theories of pathogenesis of human kidney stones suggest that calcium oxalate stone formation is a multistep process which is too complex for simple understanding, a large number of protein molecules involved are still unknown and uninvestigated.

Crystal-cell interaction model is widely used for kidney stone research for better understanding of the pathogenic mechanisms of kidney stone formation [18].
MDCK renal tubular cells (a cell line derived from dog kidney exhibiting distal renal tubule phenotype) and HK-2 cells (an immortalized human kidney proximal tubule epithelial cell line) are the most frequently used cells in crystal-cell interaction model [18]. Although several previous studies have found some new candidate proteins, further studies are necessary, since the COMcrystals prepared by calcium chloride dihydrate and sodium oxalate are different from the clinical COM-stone samples and use of cells from different species of the nephron may result in different findings. We used HK-2 cells for it was derived from adult human kidney proximal tubule which is the major site of renal oxalate handling [19], represents a major potential advantage over currently available animal or human embryonic derived cell lines [20].

In this study, we aim to use TMT (Tandem Mass Tag)-based quantitative proteomics analysis to investigate the effects of calcium oxalate crystal on the differential protein expression profiles of human renal tubular epithelial cell HK-2, screen differentially expressed protein molecules and initially explore their functional roles in calcium oxalate stone formation and its resulting renal damage.

\section{Methods \\ Cell culture}

The immortalized proximal tubule epithelial cell line HK-2 (human kidney-2) was purchased from Bogoo Biotechnology.Co., Ltd. (Cat. BG005, Shanghai, China), and cultured with DMEM medium supplemented with $10 \%$ fetal bovine serum, 100 units $/ \mathrm{ml}$ penicillin sodium, and $100 \mu \mathrm{g} / \mathrm{ml}$ streptomycin as described previously [14]. Cultures were maintained at $37{ }^{\circ} \mathrm{C}$ with $5 \% \mathrm{CO} 2$ and saturated humidity [21-23].

\section{COM crystal preparation}

The calcium oxalate kidney stone specimen used in this study was obtained from the Department of Urology, People's Hospital of Longhua Shenzhen in 2018. After characterization by a stone component analyzer (LIIR20, Lambda scientific, Tianjin China), the calcium oxalate kidney stone was fully crushed into powder by sterilized mortar and pestle and then prepared into COM suspension. Briefly, the crystals were suspended with serum-free DMEM at a final concentration of $100 \mu \mathrm{g} /$ $\mathrm{mL}$ (per volume of medium) [14, 24], which was demonstrated not to cause severe cytotoxicity to renal tubular cells or increase percentage of cell death [24], but induce alterations in cellular proteome and reflect response of the renal epithelial cells to the COM crystals in vivo [18, $24,25]$. The kidney stone specimen was used in accordance with the hospital ethical review and the patient's informed consent. 


\section{Protein extraction and quality analyzation}

HK-2 cells were seeded into 6-well plates at a density of $1 \times 10^{5}$ cells per well and divided into two groups $(n=3$ per group) when the cell density reached $70-80 \%$ confluence. The culture medium was replaced by either COM-crystal containing medium (with $100 \mu \mathrm{g} / \mathrm{mL} \mathrm{COM}$ crystals) or COM-free medium. The cells were further maintained for $24 \mathrm{~h}$. Cell pictures were taken after incubation by a microscope (GMSP-5, Shanghai Guangmi instrument Co.,ltd). Cell samples were harvested by cell scraping, repeatedly frozen and thawed, and then sonicated on ice for $2 \mathrm{~min}$; After $4{ }^{\circ} \mathrm{C}, 12000 \mathrm{~g}$ centrifugation for $20 \mathrm{~min}$, protein supernatant was collected for BCA quantification and SDS-PAGE electrophoresis.

\section{TMT-based quantitative proteomic analysis}

TMT (Tandem Mass Tag) technology is a peptide in vitro labeling technology developed by Thermo Scientific, USA. The technology uses 10 isotopic labels to label the amino group of the peptide. After LC-MS/MS analysis, peak identification was performed to obtain a peak list and a reference database was established to identify peptides and proteins. Samples were analyzed by Shanghai Majorbio bio-pharm Biotechnology Co. Ltd. (Shanghai, China). The differential expressed proteins were screened based on the significance of $p$ values, and the differentially expressed proteins were subjected to bioinformatics.

\section{GO and KEGG enrichment analysis}

GO (Gene Ontology, http://www.geneontology.ory/) is a comprehensive database of gene-related research results from all over the world. The significant functional enrichment analysis of the differential proteins can explain the functional enrichment of the differential proteins and clarify the differences in the sample components at the functional level. This study used Goatools for enrichment analysis using Fisher's exact test. KEGG (Kyoto Encyclopedia of Genes and Genomes) is a database resource for understanding high-level functions and utilities of the biological system, so we used KOBAS software to test the statistical enrichment of differential expression proteins in KEGG pathways.

\section{Differential protein interaction network analysis}

The Search Tool for the Retrieval of Interacting Genes (STRING) database (http://string-db.org/), a database that provides experimental and predicted proteins interaction information [26], was used to build proteinprotein interaction networks. In addition to mining data including experimental data and various databases, comprehensive scoring $(0.4-1)$ is performed from the aspects of chromosome proximity, gene fusion, phylogenetics and gene-based co-expression based on chip data, thereby predicting the inter-protein interactions. Each node in the network represents a protein molecule, and the line represents the interaction between proteins. The wider the line, the higher the score, and the narrower the line, the lower the score. In this study, the cutoff confidence score of protein-interactions was $\geq 0.4$.

\section{Statistics}

Statistical analysis was performed using SPSS17.0 software. Quantitative data were analyzed by one-way ANOVA. Those with irregular variance were analyzed by rank sum test. Differences between samples were analyzed by LSD method, and the results were expressed as mean \pm standard deviation. The difference was statistically significant at $p<0.05$.

\section{Results}

Preparation of kidney stone treated HK-2 cells and quality control of TMT mass spectrometry samples

The human proximal tubular epithelial cell HK-2 cells were suspended into single cells, seeded onto 6-well plates overnight. Crystal suspension of calcium oxalate stone with a final concentration of $100 \mu \mathrm{g} / \mathrm{ml}$ was added and incubated for $24 \mathrm{~h}$. The calcium oxalate crystals adhered to the surface of HK-2 cells was clearly observed by phase-contrast microscopy (Fig. 1a). These COM crystals adhere tightly to the surface of the cells, which even cannot be removed by several washes with PBS. After incubation, cells were harvested by scraping, and prepared for quality control prior to TMT analysis. Quality control results showed that 24,224 proteins were identified in 122,920 identified spectrum (Fig. 1b). Protein coverage distribution analysis showed that 4137 proteins were covered over 10\% (Fig. 1c), suggesting that the sample preparation was successful and could be proceeded for TMT analyzation.

\section{Proteome alterations of HK-2 cells after adhered by calcium oxalate crystals}

The screening criteria for significant differentially expressed proteins (DEPs) were $p<0.05$ and $F C<0.83$ or $F C>1.20$. The scatter plot of the DEPs is shown in Fig. 2a. Results showed that among the total number of 6407 target proteins, 1141 (17.8\%) proteins changed significantly, of which 699 (61.3\%) proteins were upregulated (Fig. 2b), 442 (38.7\%) proteins were downregulated expression. The proteins with $p>0.05$ and $F C>2$ (Table 1) or $F C<0.6$ (Table 2) were selected for further bioinformatics analyzation.

\section{Cluster analysis of differentially expressed proteins}

Two-dimensional hierarchical clustering feature of the 40 selected DEPs was presented in a heatmap (Fig. 3). Columns in the heat map represents COM-treated 


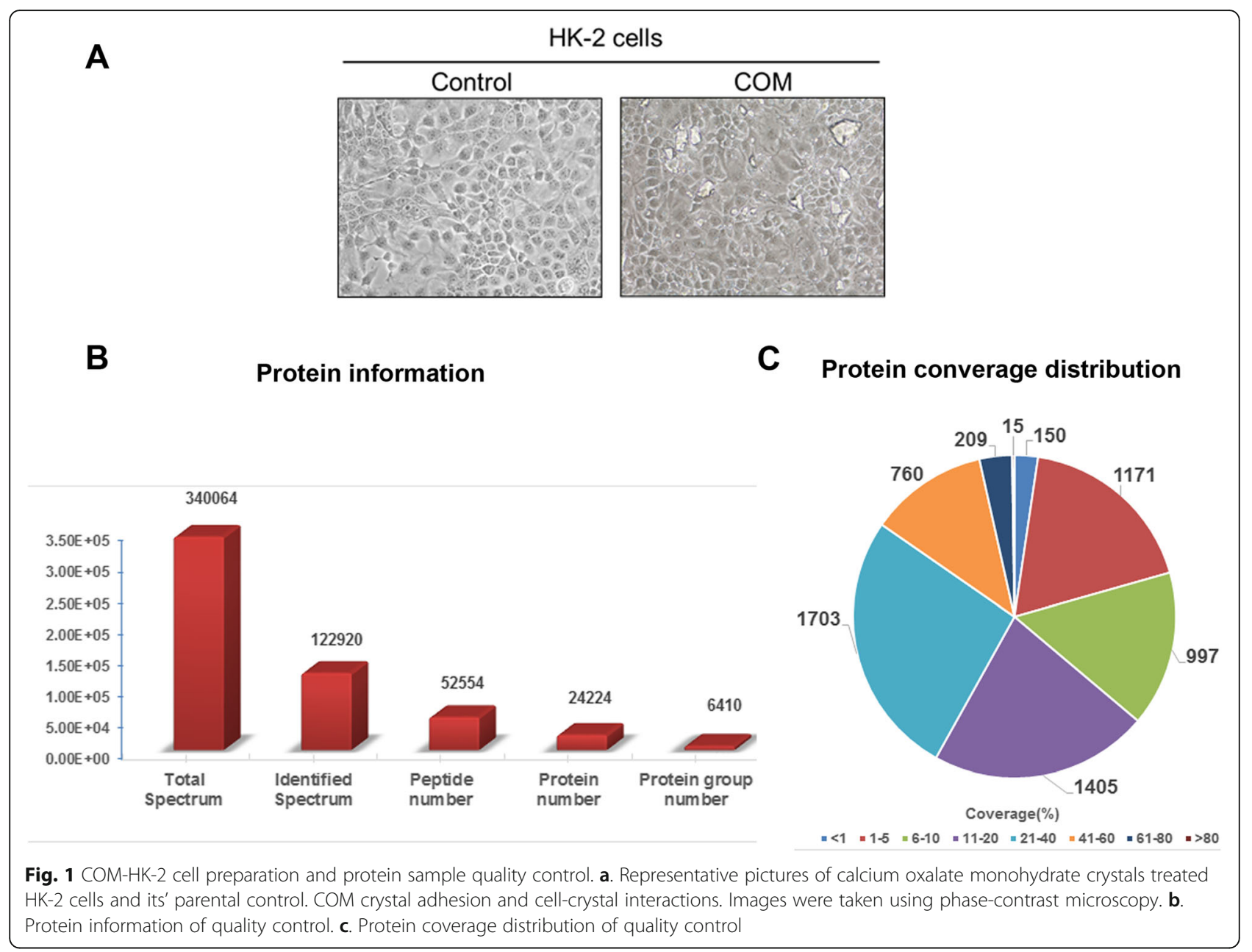

A

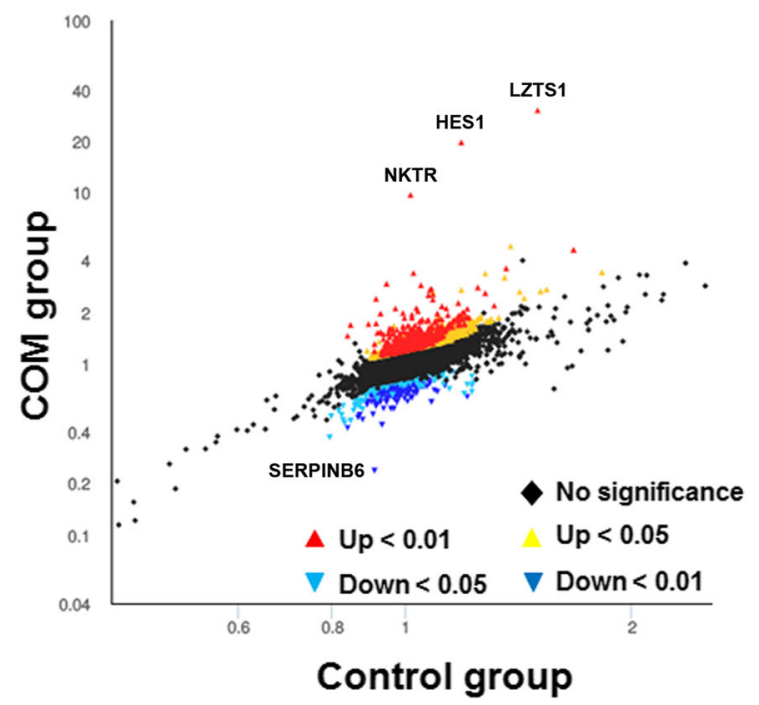

B

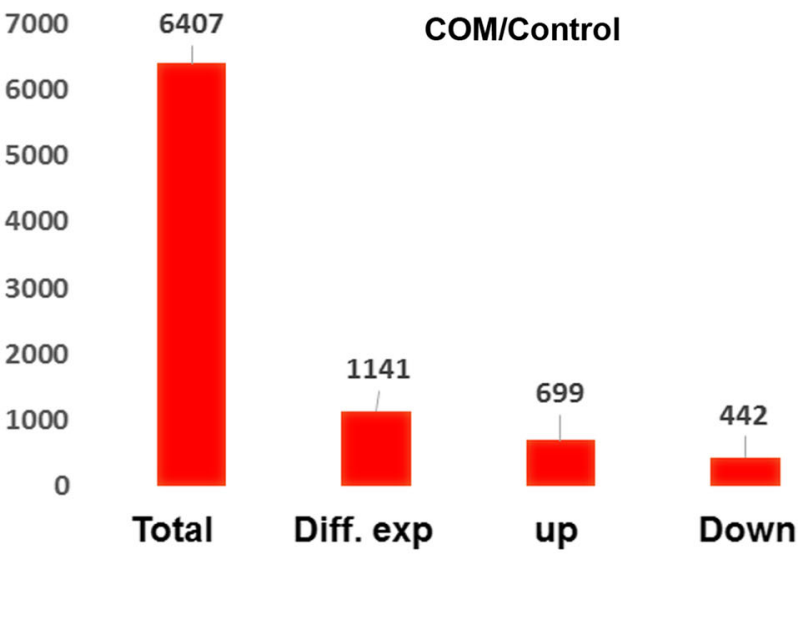

Fig. 2 Proteome alterations of HK-2 cells after treated with calcium oxalate crystals. a. Scatter plot of differential expressed proteins statistics. b. Histogram of differential expressed proteins 
Table 1 Upregulated proteins in COM-stimulated HK-2 cells $(P<0.05, F C>2)$

\begin{tabular}{|c|c|c|c|c|}
\hline Gene name & Accession & $\mathrm{FC}(\mathrm{C} / \mathrm{H})$ & $\boldsymbol{P}$ value $(\mathrm{C} / \mathrm{H})$ & Description \\
\hline LZTS1 & Q9Y250 & 20.20 & 0.001 & Leucine zipper putative tumor suppressor $1 \mathrm{OS}=$ Homo sapiens GN $=\mathrm{LZTS} 1 \mathrm{PE}=1 \mathrm{SV}=3$ \\
\hline HES1 & Q14469 & 16.53 & 0.001 & Transcription factor HES-1 OS=Homo sapiens GN=HES1 PE = 1 SV = 1 \\
\hline NKTR & P30414 & 9.53 & 0.001 & NK-tumor recognition protein OS=Homo sapiens GN=NKTR PE $=1$ SV $=2$ \\
\hline KLK15 & MOR2F7 & 3.51 & 0.033 & Kallikrein-15 (Fragment) OS=Homo sapiens GN=KLK15 PE = 4 SV = 1 \\
\hline CLPS & P04118 & 3.30 & 0.002 & Colipase OS=Homo sapiens GN=CLPS PE = 1 SV = 2 \\
\hline DPP8 & Q6V1X1 & 3.09 & 0.004 & Dipeptidyl peptidase 8 OS=Homo sapiens GN = DPP8 PE $=1$ SV = 1 \\
\hline CEP128 & Q6ZU80 & 2.77 & 0.004 & Centrosomal protein of $128 \mathrm{kDa}$ OS=Homo sapiens GN=CEP128 PE = $1 \mathrm{SV}=2$ \\
\hline PHRF1 & Q9P1Y6 & 2.74 & 0.003 & PHD and RING finger domain-containing protein $1 \mathrm{OS}=$ Homo sapiens GN=PHRF1 PE $=1 \mathrm{SV}=3$ \\
\hline HNRNPD & D6RBQ9 & 2.64 & 0.007 & $\begin{array}{l}\text { Heterogeneous nuclear ribonucleoprotein D0 (Fragment) OS=Homo sapiens GN=HNRNPD } \\
\mathrm{PE}=1 \mathrm{SV}=1\end{array}$ \\
\hline ANXA2 & HOYL33 & 2.63 & 0.015 & Annexin (Fragment) OS=Homo sapiens GN $=$ ANXA2 PE $=1 \mathrm{SV}=1$ \\
\hline TMEM141 & Q96145 & 2.61 & 0.000 & Transmembrane protein 141 OS=Homo sapiens GN = TMEM141 PE = 1 SV=1 \\
\hline FAU & E9PM49 & 2.53 & 0.001 & $40 \mathrm{~S}$ ribosomal protein $\mathrm{S} 30$ (Fragment) OS=Homo sapiens GN=FAU PE $=1 \mathrm{SV}=8$ \\
\hline TMSB10 & P63313 & 2.49 & 0.009 & Thymosin beta-10 OS=Homo sapiens GN $=$ TMSB10 PE $=1 \mathrm{SV}=2$ \\
\hline CFL1 & E9PP50 & 2.38 & 0.013 & Cofilin-1 (Fragment) OS=Homo sapiens GN=CFL1 PE = 1 SV = 8 \\
\hline RPS29 & P62273 & 2.35 & 0.024 & $40 S$ ribosomal protein $\mathrm{S} 29 \mathrm{OS}=$ Homo sapiens GN $=\mathrm{RPS} 29 \mathrm{PE}=1 \mathrm{SV}=2$ \\
\hline ACTB & C9JTX5 & 2.34 & 0.000 & Actin, cytoplasmic 1 (Fragment) OS=Homo sapiens GN = ACTB PE $=1 \mathrm{SV}=1$ \\
\hline ZNF12 & P17014 & 2.32 & 0.001 & Zinc finger protein $12 \mathrm{OS}=$ Homo sapiens $\mathrm{GN}=\mathrm{ZNF} 12 \mathrm{PE}=1 \mathrm{SV}=3$ \\
\hline GCHFR & P30047 & 2.27 & 0.013 & GTP cyclohydrolase 1 feedback regulatory protein OS=Homo sapiens GN $=\mathrm{GCHFR}$ PE $=1 \mathrm{SV}=3$ \\
\hline ZNF146 & Q15072 & 2.23 & 0.000 & Zinc finger protein OZF OS=Homo sapiens GN $=$ ZNF146 PE $=1 \mathrm{SV}=2$ \\
\hline TMEM222 & Q9H0R3 & 2.17 & 0.002 & Transmembrane protein 222 OS=Homo sapiens GN = TMEM222 PE = 1 SV = 2 \\
\hline ZNF574 & AOAOC4DFM2 & 2.16 & 0.000 & HCG1643764, isoform CRA_b OS=Homo sapiens GN = ZNF574 PE = 1 SV = 1 \\
\hline TSHZ1 & Q6ZSZ6 & 2.11 & 0.006 & Teashirt homolog $1 \mathrm{OS}=$ Homo sapiens GN =TSHZ1 PE $=1 \mathrm{SV}=2$ \\
\hline ITGA5 & P08648 & 2.04 & 0.007 & Integrin alpha-5 OS=Homo sapiens GN=ITGA5 PE = $1 \mathrm{SV}=2$ \\
\hline BTF3 & D6RDG3 & 2.02 & 0.004 & Transcription factor BTF3 (Fragment) OS=Homo sapiens GN=BTF3 PE $=1 \mathrm{SV}=3$ \\
\hline
\end{tabular}

Table 2 Down-regulated proteins in COM-stimulated HK-2 cells $(P<0.05, F C<0.6)$

\begin{tabular}{|c|c|c|c|c|}
\hline Gene name & Accession & $\mathrm{FC}(\mathrm{C} / \mathrm{H})$ & $\boldsymbol{P}$ value $(\mathrm{C} / \mathrm{H})$ & Description \\
\hline PRDX1 & Q06830 & 0.57 & 0.001 & Peroxiredoxin-1 OS=Homo sapiens GN=PRDX1 PE = $1 \mathrm{SV}=1$ \\
\hline NME2P1 & O60361 & 0.57 & 0.029 & Putative nucleoside diphosphate kinase OS=Homo sapiens GN=NME2P1 PE = 5 SV = 1 \\
\hline SLC39A10 & Q9ULF5 & 0.57 & 0.001 & Zinc transporter ZIP10 OS=Homo sapiens GN=SLC39A10 PE = 1 SV = 2 \\
\hline SERPINB1 & P30740 & 0.56 & 0.006 & Leukocyte elastase inhibitor OS=Homo sapiens GN=SERPINB1 PE = 1 SV = 1 \\
\hline FAM133B & Q5BKY9 & 0.56 & 0.014 & Protein FAM133B OS=Homo sapiens GN=FAM133B PE = 1 SV = 1 \\
\hline PRDX2 & P32119 & 0.56 & 0.003 & Peroxiredoxin-2 OS=Homo sapiens GN=PRDX2 PE $=1 \mathrm{SV}=5$ \\
\hline MYL12A & J3QRS3 & 0.56 & 0.012 & Myosin regulatory light chain $12 \mathrm{~A}$ OS=Homo sapiens $\mathrm{GN}=\mathrm{MYL} 12 \mathrm{~A} P \mathrm{PE}=1 \mathrm{SV}=1$ \\
\hline MYH14 & Q7Z406 & 0.55 & 0.002 & Myosin-14 OS=Homo sapiens GN = MYH14 PE = $1 \mathrm{SV}=2$ \\
\hline MAP10 & Q9P2G4 & 0.55 & 0.017 & Microtubule-associated protein $10 \mathrm{OS}=$ Homo sapiens GN $=$ MAP10 PE $=1 \mathrm{SV}=2$ \\
\hline PADI2 & Q9Y2J8 & 0.54 & 0.012 & Protein-arginine deiminase type-2 OS=Homo sapiens GN=PADI2 PE = 1 SV =2 \\
\hline C14orf1 & Q9UKR5 & 0.54 & 0.003 & Probable ergosterol biosynthetic protein $28 \mathrm{OS}=$ Homo sapiens $\mathrm{GN}=\mathrm{C} 14 \mathrm{orf1} \mathrm{PE}=1 \mathrm{SV}=1$ \\
\hline MYH9 & P35579 & 0.53 & 0.010 & Myosin-9 OS=Homo sapiens GN = MYH9 PE $=1 \mathrm{SV}=4$ \\
\hline MT-ND2 & P03891 & 0.50 & 0.010 & NADH-ubiquinone oxidoreductase chain $2 \mathrm{OS}=$ Homo sapiens $\mathrm{GN}=\mathrm{MT}-\mathrm{ND} 2 \mathrm{PE}=1 \mathrm{SV}=2$ \\
\hline APITD1-CORT & A0A087WT10 & 0.47 & 0.001 & APITD1-CORT readthrough OS=Homo sapiens GN = APITD1-CORT PE $=1 \mathrm{SV}=1$ \\
\hline TUFT1 & Q9NNX1 & 0.47 & 0.015 & Tuftelin OS=Homo sapiens GN = TUFT1 PE = 1 SV = 1 \\
\hline SERPINB6 & A0A087X1N8 & 0.26 & 0.000 & Serpin B6 OS=Homo sapiens GN=SERPINB6 PE $=1$ SV $=1$ \\
\hline
\end{tabular}




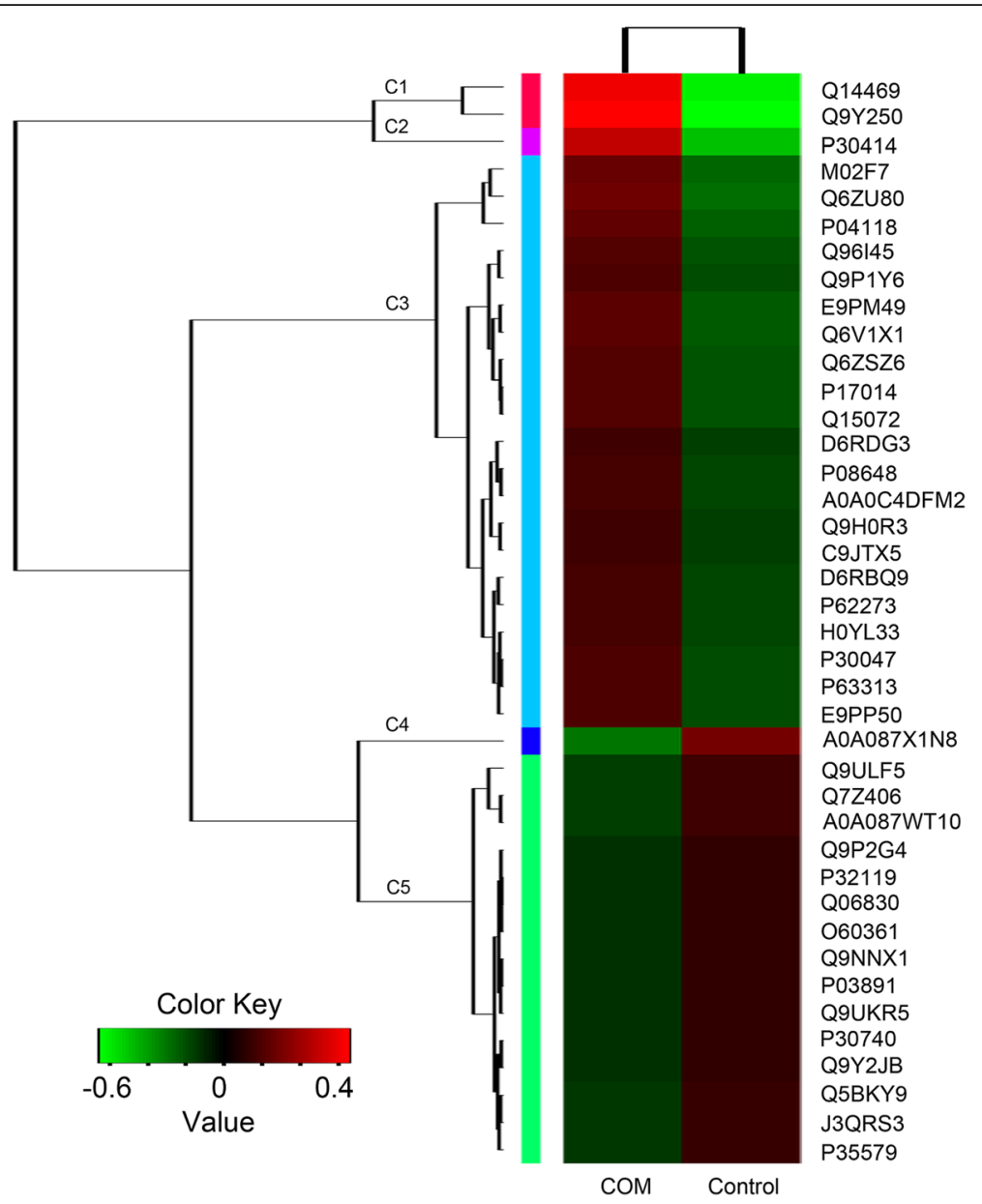

Fig. 3 Heatmap and cluster analysis of differential expressed proteins. Proteins fold change (FC) $>2$ or $<0.6$ and $p<0.05$ were enriched

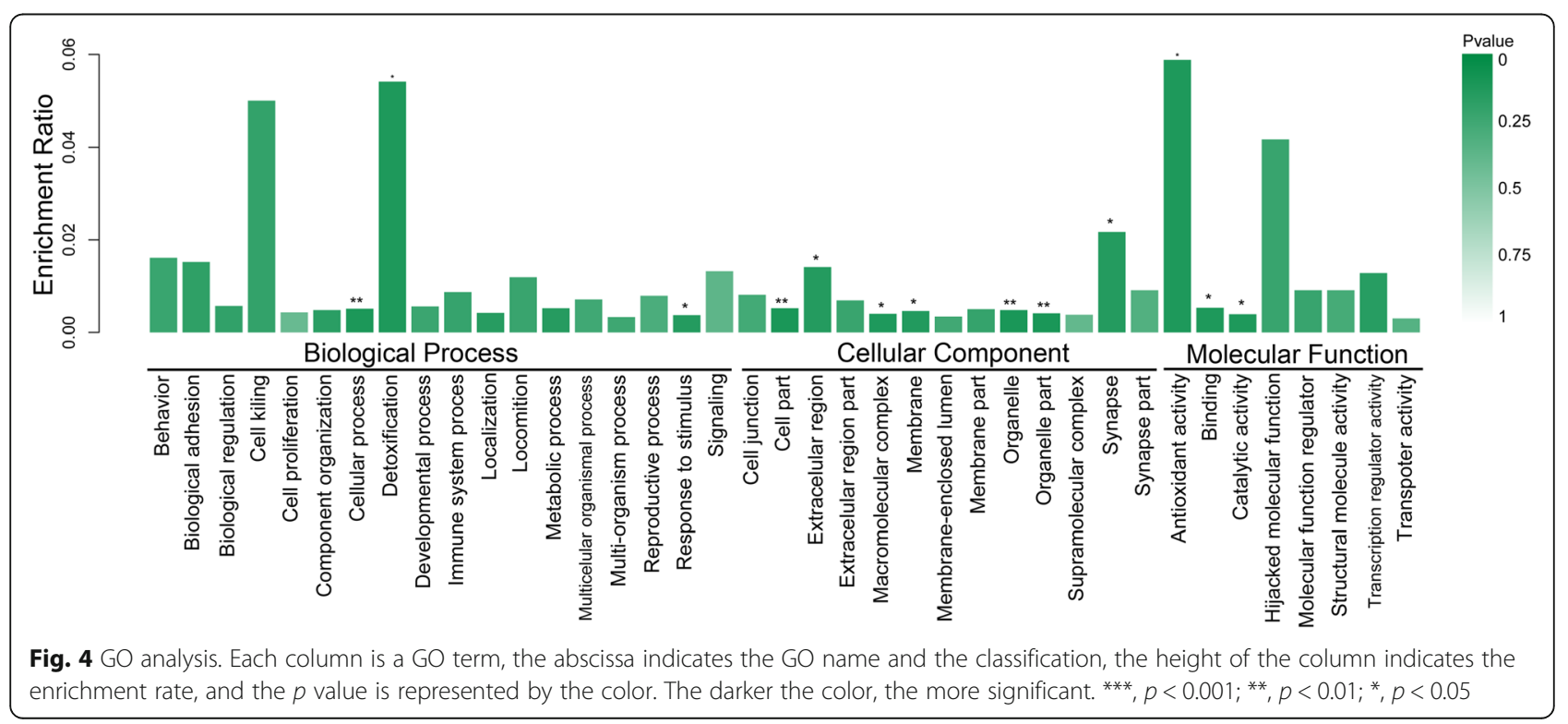


group $(n=3)$ and Control group $(n=3)$ respectively. The color in the figure indicates the relative expression of the protein in the sample, the red color indicates that the protein is expressed higher in the sample, and the green color represents the lower expression level. The trend of the amount of expression is shown in the color code. On the left is a dendrogram of protein clustering. Cluster analysis showed that the selected DEPs can be divided into 5 clusters ( $\mathrm{C} 1$ to $\mathrm{C} 5$ ) based on the heat map signal intensity. The cluster 1 (C1) included two proteins (LZTS1, HES1) which showed the highest expression level in the COM treated group compare to that in control group. The cluster 3 (C3) included 21 proteins which were higher expressed in COM treated group. By contrast, the cluster 5 (C5) consisted 15 proteins which were decreased in COM treated group.

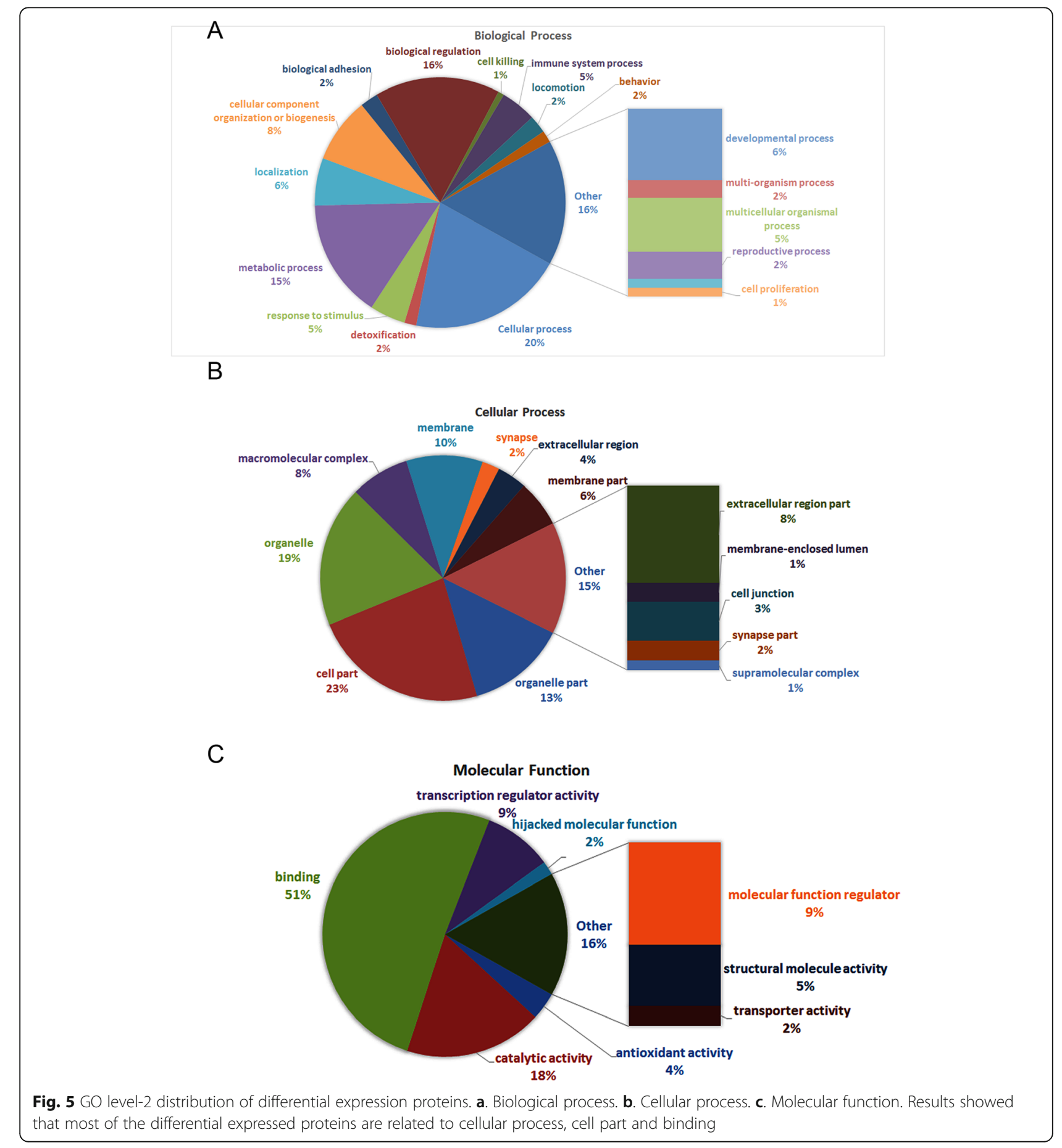


Table 3 GO terms of the differentially expressed proteins involved in COM-stimulated HK-2 cells

\begin{tabular}{llll}
\hline Name & Namespace & Count & $P$ value \\
\hline Cell part & Cellular component & 30 & 0.002 \\
Organelle & Cellular component & 24 & 0.003 \\
Membrane & Cellular component & 13 & 0.038 \\
Organelle part & Cellular component & 17 & 0.001 \\
Macromolecular complex & Cellular component & 10 & 0.021 \\
Extracellular region & Cellular component & 5 & 0.046 \\
Synapse & Cellular component & 3 & 0.044 \\
Cellular process & Biological process & 26 & 0.009 \\
Response to stimulus & Biological process & 6 & 0.046 \\
Detoxification & Biological process & 2 & 0.020 \\
Antioxidant activity & Molecular function & 2 & 0.017 \\
Binding & Molecular function & 28 & 0.019 \\
Catalytic activity & Molecular function & 10 & 0.018 \\
\hline
\end{tabular}

\section{GO and KEEG enrichment analyses}

The significant functional enrichment analysis of GO proteins on differential proteins can explain the functional enrichment of differential proteins and clarify the differences exhibited in the samples at the functional level. To investigate the biological roles of the DEPs altered by COM crystals in HK-2 cells, a categorized GO enrichment analysis was performed. According to the gene function classification of GO, the selected DEPs were mainly related to cellular process, cell part, organelles, binding and catalytic activity (Figs. 4 and 5). For the response to the COM crystals, cell part $(p=0.002)$ and cellular process $(p=0.009)$ were the most significantly enriched functional terms for cellular component (CC) and biological processes (BP), respectively. Most of the candidate proteins are involved in cellular component (CC) as showed in Table 3.

There were 11 significant pathways identified in HK-2 cells in response to COM crystals (Fig. 6 and Table 4), among which the regulation of actin cytoskeleton pathway was the most significant $(p=0.0001)$, suggested that the regulation of the actin cytoskeleton was a critical part of cellular activities in response to COM crystals adhesion.

\section{Biological interaction of differentially expressed proteins}

According to the information of STRING database, the protein-interaction networks of the selected DEPs contained 8 main nodes and 21 connects (Fig. 7). The top 3 high-score hub nodes included $\beta$-Actin (ACTN), Cofilin1 (CFL1) and Myosin-9 (MYH9). Among these proteins, the interaction between CFL1 and ACTN, which were both up-regulated in COM-treated HK-2 cells, exhibited the highest combined score of 0.999 . These proteins and interactions may play vital roles in $\mathrm{HK}-2$ cells in response to the COM crystals adhesion.

\section{Discussion}

Kidney stone is a common urological disease with high incidence, which remains a common health problem worldwide. At present, the mechanism of kidney stone formation is not fully understood. One of the favored

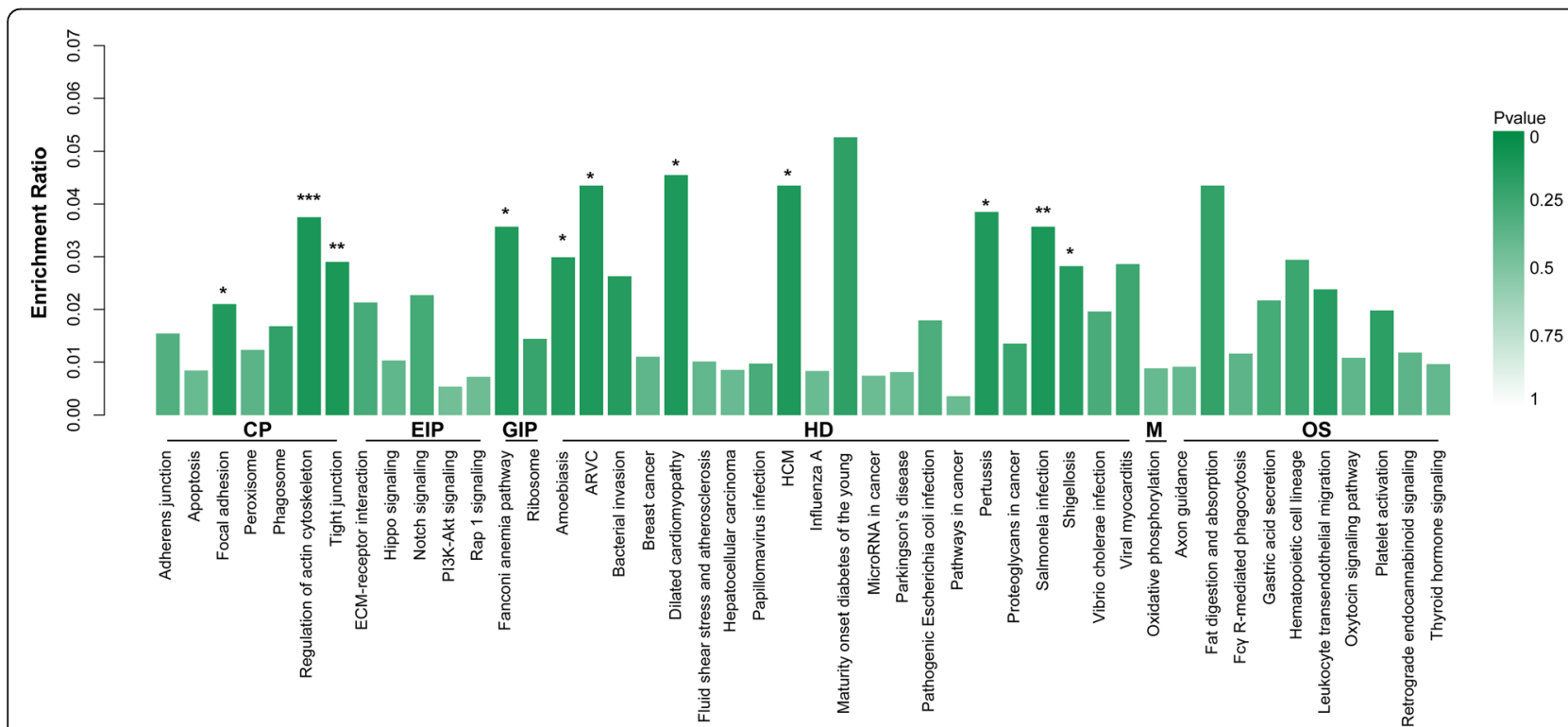

Fig. 6 KEEG analysis. Each column is a pathway, the abscissa indicates the name and the classification, the height of the column indicates the enrichment rate, and the $p$ value is represented by the color. The darker the color, the more significant. Results showed that 11 pathways were significant changed in the COM treated HK-2 cells as compared to its untreated control. ${ }^{* * *}, p<0.001 ;{ }^{* *}, p<0.01 ;{ }^{*}, p<0.05$ 
Table 4 KEGG pathway analysis of the differentially expressed proteins involved in COM-stimulated HK-2 cells

\begin{tabular}{|c|c|c|c|}
\hline Pathway & Class & Count & $\boldsymbol{p}$ value \\
\hline Regulation of actin cytoskeleton & Cellular Processes & 6 & 0.0001 \\
\hline Tight junction & Cellular Processes & 4 & 0.004 \\
\hline Focal adhesion & Cellular Processes & 3 & 0.0294 \\
\hline Salmonella infection & Human Diseases & 3 & 0.0076 \\
\hline Dilated cardiomyopathy (DCM) & Human Diseases & 2 & 0.0195 \\
\hline Arrhythmogenic right ventricular cardiomyopathy (ARVC) & Human Diseases & 2 & 0.0211 \\
\hline Hypertrophic cardiomyopathy (HCM) & Human Diseases & 2 & 0.0211 \\
\hline Pertussis & Human Diseases & 2 & 0.0264 \\
\hline Amoebiasis & Human Diseases & 2 & 0.041 \\
\hline Shigellosis & Human Diseases & 2 & 0.0453 \\
\hline Fanconi anemia pathway & Genetic Information Processing & 2 & 0.0301 \\
\hline
\end{tabular}

theories suggests that the calcium oxalate-induced injury to renal tubular epithelial cells promotes the adherence and acumination of calcium oxalate crystals results in stone formation [27]. Given proteins are the major component of kidney stone organic matrix and considered to play a regulatory function in cell-crystal interactions and lithogenesis inside the kidney [28-31], we selected immortalized human proximal tubular epithelial cells HK-2 exposure to COM crystals to generate the cell-crystal interaction model and analyzed the altered proteomic landscape in HK-2 cells in response to COM adhesion.

In this study, we first systematically screened the DEPs profiles in COM-HK-2 model by TMT-labeled quantitative proteomics analysis. Of the 1141 identified DEPs,
699 (61.3\%) proteins were up-regulated, 442 (38.7\%) proteins were down-regulated. By contrast, a similar previous study performed by Chen et al. in 2010 [32] demonstrated that only 12 DEPs were identified in HK-2 cells after COM crystals stimulation. This different observation may due to the limits of methodology used by Chen et al. in their study. Here, gel-free TMT-based quantitative proteomic approach uses isobaric labels and allows for genome-wide quantitation of differences in protein expression levels [33], proved to be a more reliable and reproducible technology to analyze complex samples.

Several of proteins have been characterized to play critical roles in kidney stone formation, however, the

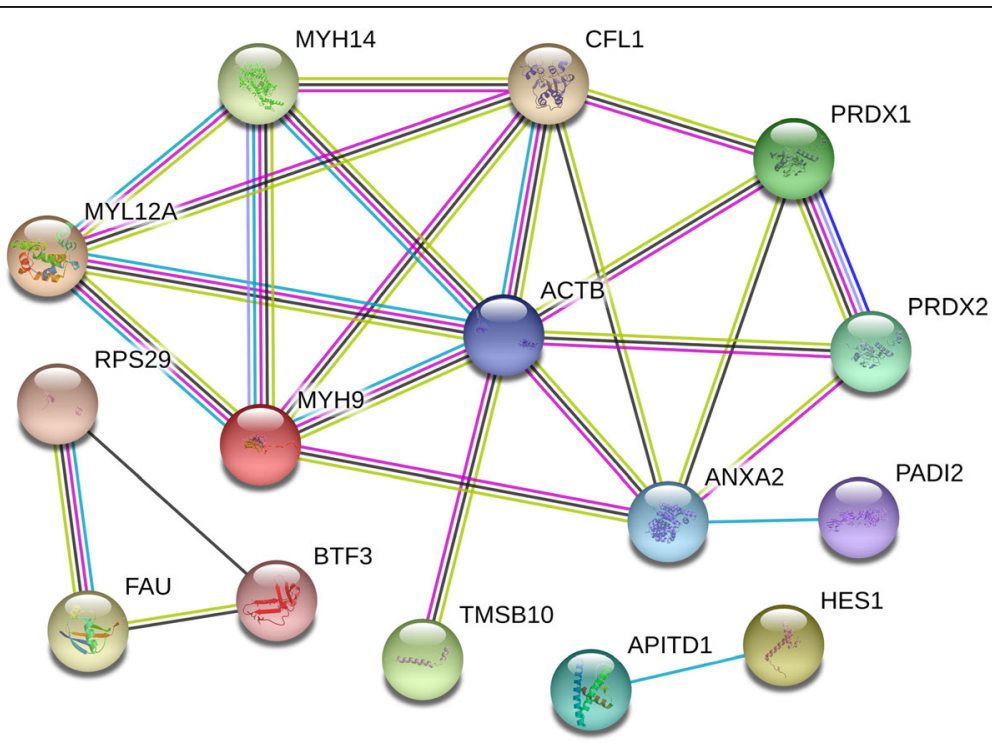

Fig. 7 Protein interaction networks of differential expressed proteins. According to the STRING database, the protein interaction networks of the DEPs contained 8 main nodes and 21 connections. Each node in the network represents a protein molecule, and the line represents the interaction between proteins. The wider the line, the higher the score, and the narrower the line, the lower the score. The top 3 high-score hub nodes included CFL1, ACTN and MYH9. The interaction between CFL1 and ACTN exhibited the highest combined score of 0.999, suggested that may play vital roles in the adhesion of COM to the HK-2 cells 
mechanisms involved are far from clear. Tamm-Horsfall protein (THP) was identified as a kidney-specific protein, serve as a key regulator in promoting the aggregation of calcium-salt crystals and stone formation [34, 35], which is a potent immunomodulatory molecule and a disease biomarker in the urinary system [35]. Osteopontin (OPN) is another important component of calcium oxalate stone matrix [29], plays an important role in preventing the formation of calcium oxalate monohydrate (COM) kidney stones, which controls switching of calcium oxalate monohydrate morphologies in urine [36] to promote the formation of stones by promoting crystal adhesion and mediating oxidative stress and apoptosis [17, 37].

In this study, we identified that the LZTS1 (leucine zipper hypothetical tumor suppressor gene 1) protein, a full-length 596 amino acid protein with a molecular weight of $67 \mathrm{kD}$, was significantly upregulated in COM adhered HK-2 cells. Though the role and mechanism involved of LZTS1 protein was well studied in various types of malignant tumors such as stomach, lung, bladder, ovary, and kidney [38], the functional role of LZTS1 in kidney stone disease is unreported. The HES1 (hairy enhancer of split 1) protein, the core effector of $\mathrm{NOTCH}$ signaling pathway and considered to be a good indicator of the activation of the NOTCH signaling pathway [39, 40], exhibited significant reduce expression in COM adhered HK-2 cells. Present study is the first report to demonstrate the relation between the HES1 protein and kidney stone formation and its associated kidney injury, however, further study of the mechanism involved is in need.

Our bioinformatics analysis indicated that the GO terms of cellular process, cell part, organelles, binding and catalytic activity are significant changed in COM adhered HK-2 cells, suggested that these processes or cell structures and its related proteins are widely involved in kidney stone formation. The enriched signaling pathway identified by KEEG analysis were regulation of the actin cytoskeleton, tight junction and focal adhesion. Of these, the regulation of actin cytoskeleton showed the most significance, which plays vital roles in response to extracellular signals, spatially and temporally regulates adhesions, protrusion, contraction, and retraction [41]. Meanwhile, we analyzed the protein interaction networks of the selected DEPs and found that the CFL1, ACTN and MYH9 were the 3 high-degree hub nodes and may be involved in the pathological processes of HK-2 cells in response to the COM crystals adhesion. These findings suggested that the cell structure- and cell actin cytoskeleton dynamics had been significantly changed by COM crystals.

\section{Conclusion}

We screened and identified key protein molecules that may be involved in the formation of calcium oxalate kidney stones, and revealed the possible signaling pathways and related disease processes, providing important potential targets and interactions for further elucidation of the pathogenesis of kidney stones. However, despite these comprehensive bioinformatics analyses, the current study has several limitations. HK-2 cells are not normal proximal tubular cells, which is a big limitation of the present study. Furthermore, the in vitro COM concentration could not perfectly mimic the status of crystals in kidney, the dose-dependent and time-dependent effects of COM stimulation were not involved. In our future investigations, we hope to perform additional proteomics analyses on normal proximal tubular cells/animal models of different time points and experimental validation to enrich this study.

\section{Abbreviations \\ COM: Calcium Oxalate Monohydrate; DEP: Differential expression protein; TMT: Tandem Mass Tag; KEEG: Kyoto Encyclopedia of Genes and Genomes; GO: Gene Ontology; CC: Cellular Component; BP: Biological Processes; MF: Molecular Function; OS: Organismal Systems; HD: Human Diseases; CP: Cellular Processes; EIP: Environmental Information Processing; \\ GIP: Genetic Information Processing; M: Metabolism}

\section{Acknowledgments}

Not applicable.

\section{Authors' contributions}

ZW and ML examined and scripted the manuscript. ZW obtained funding for the study, drafted and revised the manuscript. CX, QD and RS performed the experiments and statistical analysis; $Y Z, J Z$ and $S Z$ helped to analyze the data and draft the manuscript. $\mathrm{QH}$ and $\mathrm{HL}$ supported for the critical revision of the manuscript for intellectual content. All authors read and approved the final manuscript.

\section{Funding}

This study was financially supported by National Natural Science Foundation of China (grant no. 81802566, Z. Wang), and Shenzhen Science and Technology Program (Basic Research Project, grant no.

JCYJ20180228163919346, Z. Wang). Funds were used for purchasing reagents, materials, sequencing fees and publication fees. Both funding sources were uninvolved in study design, data acquisition, analysis and interpretation, as well as manuscript drafting and revision.

\section{Availability of data and materials}

The datasets used during the current study are available from the corresponding author on reasonable request.

Ethics approval and consent to participate Not Applicable.

\section{Consent for publication}

Not Applicable.

\section{Competing interests}

The authors declare seriously that external funding sources and interest conflicts did not exist in the study.

\section{Author details}

${ }^{1}$ Department of Urology, People's Hospital of Longhua, Southern Medical University, Shenzhen 518109, Guangdong, China. 'Laboratory of Molecular Pharmacology, Department of Pharmacology, School of Pharmacy,

Southwest Medical University, Luzhou 646000, Sichuan, China. ${ }^{3}$ Department of Laboratory Medicine, Third Affiliated Hospital of Sun Yat-sen University, Guangzhou, Guangdong 510630, People's Republic of China. 


\section{Received: 11 November 2019 Accepted: 26 August 2020}

\section{Published online: 31 August 2020}

\section{References}

1. Trinchieri A, Coppi F, Montanari E, Del Nero A, Zanetti G, Pisani E. Increase in the prevalence of symptomatic upper urinary tract stones during the last ten years. Eur Urol. 2000;37(1):23-5. https://doi.org/10.1159/000020094.

2. Wang W, Fan J, Huang G, Li J, Zhu X, Tian Y, Su L. Prevalence of kidney stones in mainland China: a systematic review. Sci Rep. 2017;7:41630. https://doi.org/10.1038/srep41630.

3. Zeng G, Mai Z, Xia S, Wang Z, Zhang K, Wang L, Long Y, Ma J, Li Y, Wan SP, Wu W, Liu Y, Cui Z, Zhao Z, Qin J, Zeng T, Liu Y, Duan X, Mai X, Yang Z, Kong Z, Zhang T, Cai C, Shao Y, Yue Z, Li S, Ding J, Tang S, Ye Z. Prevalence of kidney stones in China: an ultrasonography based cross-sectional study. BJU Int. 2017;120(1):109-16. https://doi.org/10.1111/bju.13828.

4. Leveridge M, D'Arcy FT, O'Kane D, Ischia JJ, Webb DR, Bolton DM, Lawrentschuk N. Renal colic: current protocols for emergency presentations. Eur J Emerg Med. 2016;23(1):2-7. https://doi.org/10.1097/MEJ. 0000000000000324.

5. Worcester EM, Coe FL. Clinical practice. Calcium kidney stones. N Engl J Med. 2010;363(10):954-63. https://doi.org/10.1056/NEJMcp1001011.

6. Wang B, Wu B, Liu J, Yao W, Xia D, Li L, Chen Z, Ye Z, Yu X. Analysis of altered microRNA expression profiles in proximal renal tubular cells in response to calcium oxalate monohydrate crystal adhesion: implications for kidney stone disease. PLoS One. 2014;9(7):e101306. https://doi.org/10.1371/ journal.pone.0101306.

7. Khan SR. Role of renal epithelial cells in the initiation of calcium oxalate stones. Nephron Exp Nephrol. 2004;98(2):e55-60. https://doi.org/10.1159/ 000080257.

8. Qin B, Wang Q, Lu Y, Li C, Hu H, Zhang J, Wang Y, Zhu J, Zhu Y, Xun Y, Wang S. Losartan ameliorates calcium oxalate-induced elevation of stonerelated proteins in renal tubular cells by inhibiting NADPH oxidase and oxidative stress. Oxidative Med Cell Longev. 2018;2018:1271864. https://doi. org/10.1155/2018/1271864.

9. Joshi S, Peck AB, Khan SR. NADPH oxidase as a therapeutic target for oxalate induced injury in kidneys. Oxidative Med Cell Longev. 2013;2013: 462361. https://doi.org/10.1155/2013/462361.

10. Zuo J, Khan A, Glenton PA, Khan SR. Effect of NADPH oxidase inhibition on the expression of kidney injury molecule and calcium oxalate crystal deposition in hydroxy-L-proline-induced hyperoxaluria in the male SpragueDawley rats. Nephrol Dial Transplant. 2011;26(6):1785-96. https://doi.org/10. 1093/ndt/gfr035.

11. Narula S, Tandon S, Singh SK, Tandon C. Kidney stone matrix proteins ameliorate calcium oxalate monohydrate induced apoptotic injury to renal epithelial cells. Life Sci. 2016;164:23-30. https://doi.org/10.1016/j.lfs.2016.08.026.

12. Evan AP, Worcester EM, Coe FL, Williams J Jr, Lingeman JE. Mechanisms of human kidney stone formation. Urolithiasis. 2015;43(Suppl 1):19-32. https:// doi.org/10.1007/s00240-014-0701-0.

13. Vinaiphat A, Aluksanasuwan S, Manissorn J, Sutthimethakorn S, Thongboonkerd $\mathrm{V}$. Response of renal tubular cells to differential types and doses of calcium oxalate crystals: integrative proteome network analysis and functional investigations. Proteomics. 2017;17(15-16). https://doi.org/10. 1002/pmic.201700192

14. Wang Z, Zhang JW, Zhang Y, Zhang SP, Hu QY, Liang H. Analyses of long non-coding RNA and mRNA profiling using RNA sequencing in calcium oxalate monohydrate-stimulated renal tubular epithelial cells. Urolithiasis. 2019;47(3):225-34. https://doi.org/10.1007/s00240-018-1065-7.

15. Martelli C, Marzano V, lavarone F, Huang L, Vincenzoni F, Desiderio C, Messana I, Beltrami P, Zattoni F, Ferraro PM, Buchholz N, Locci G, Faa G, Castagnola M, Gambaro G. Characterization of the protein components of matrix stones sheds light on S100-A8 and S100-A9 relevance in the inflammatory pathogenesis of these rare renal calculi. J Urol. 2016;196(3): 911-8. https://doi.org/10.1016/j.juro.2016.04.064.

16. Kolbach-Mandel AM, Mandel NS, Cohen SR, Kleinman JG, Ahmed F, Mandel IC, Wesson JA. Guaifenesin stone matrix proteomics: a protocol for identifying proteins critical to stone formation. Urolithiasis. 2017:45(2):13949. https://doi.org/10.1007/s00240-016-0907-4.

17. Asselman M, Verhulst A, De Broe ME, Verkoelen CF. Calcium oxalate crystal adherence to hyaluronan-, osteopontin-, and CD44-expressing injured/ regenerating tubular epithelial cells in rat kidneys. J Am Soc Nephrol. 2003; 14(12):3155-66. https://doi.org/10.1097/01.asn.0000099380.18995.f7.
18. Thongboonkerd V. Proteomics of crystal-cell interactions: a model for kidney stone research. Cells. 2019;8(9). https://doi.org/10.3390/cells8091076.

19. Shum DK, Liong E. Calcium oxalate crystallizing properties of polyanions elaborated by cultured renal proximal tubular cells. Urol Res. 1995;23(2):10310. https://doi.org/10.1007/bf00307940.

20. Ryan MJ, Johnson G, Kirk J, Fuerstenberg SM, Zager RA, Torok-Storb B. HK-2: an immortalized proximal tubule epithelial cell line from normal adult human kidney. Kidney Int. 1994;45(1):48-57. https://doi.org/10.1038/ki.1994. 6.

21. Wang Z, Wang Y, Zhang J, Hu Q, Zhi F, Zhang S, Mao D, Zhang Y, Liang H. Significance of the TMPRSS2:ERG gene fusion in prostate cancer. Mol Med Rep. 2017;16(4):5450-8. https://doi.org/10.3892/mmr.2017.7281.

22. Wang Z, Yin J, Li M, Shen J, Xiao Z, Zhao Y, Huang C, Zhang H, Zhang Z, Cho $\mathrm{CH}, \mathrm{Wu}$ X. Combination of shikonin with paclitaxel overcomes multidrug resistance in human ovarian carcinoma cells in a P-gpindependent manner through enhanced ROS generation. Chin Med. 2019; 14:7. https://doi.org/10.1186/s13020-019-0231-3.

23. Wu D, Wang Z, Lin M, Shang Y, Wang F, Zhou J, Wang F, Zhang X, Luo X, Huang W. In vitro and in vivo antitumor activity of Cucurbitacin C, a novel natural product from cucumber. Front Pharmacol. 2019;10:1287. https://doi. org/10.3389/fphar.2019.01287.

24. Thongboonkerd V, Semangoen T, Sinchaikul S, Chen ST. Proteomic analysis of calcium oxalate monohydrate crystal-induced cytotoxicity in distal renal tubular cells. J Proteome Res. 2008;7(11):4689-700. https://doi.org/10.1021/ pr8002408.

25. Semangoen T, Sinchaikul S, Chen ST, Thongboonkerd V. Proteomic analysis of altered proteins in distal renal tubular cells in response to calcium oxalate monohydrate crystal adhesion: implications for kidney stone disease. Proteomics Clin Appl. 2008;2(7-8):1099-109. https://doi.org/10. 1002/prca.200780136.

26. Franceschini A, Szklarczyk D, Frankild S, Kuhn M, Simonovic M, Roth A, Lin J, Minguez $P$, Bork $P$, von Mering $C$, Jensen LJ. STRING v9.1: protein-protein interaction networks, with increased coverage and integration. Nucleic Acids Res. 2013;41(Database issue):D808-15. https://doi.org/10.1093/nar/ gks1094.

27. Aggarwal KP, Narula S, Kakkar M, Tandon C. Nephrolithiasis: molecular mechanism of renal stone formation and the critical role played by modulators. Biomed Res Int. 2013;2013:292953. https://doi.org/10.1155/ 2013/292953.

28. Wesson JA, Kolbach-Mandel AM, Hoffmann BR, Davis C, Mandel NS. Selective protein enrichment in calcium oxalate stone matrix: a window to pathogenesis? Urolithiasis. 2019. https://doi.org/10.1007/s00240-019-01131-3.

29. Narula S, Tandon S, Baligar P, Singh SK, Tandon C. Human kidney stone matrix: latent potential to restrain COM induced cytotoxicity and inflammatory response. Chem Biol Interact. 2017;278:114-22. https://doi.org/ 10.1016/j.cbi.2017.10.018.

30. Taguchi K, Hamamoto S, Okada A, Unno R, Kamisawa H, Naiki T, Ando R, Mizuno K, Kawai N, Tozawa K, Kohri K, Yasui T. Genome-wide gene expression profiling of Randall's plaques in calcium oxalate stone formers. J Am Soc Nephrol. 2017;28(1):333-47. https://doi.org/10.1681/ASN. 2015111271.

31. Okumura N, Tsujihata M, Momohara C, Yoshioka I, Suto K, Nonomura N, Okuyama A, Takao T. Diversity in protein profiles of individual calcium oxalate kidney stones. PLoS One. 2013;8(7):e68624. https://doi.org/10.1371/ journal.pone.0068624.

32. Chen S, Gao X, Sun Y, Xu C, Wang L, Zhou T. Analysis of HK-2 cells exposed to oxalate and calcium oxalate crystals: proteomic insights into the molecular mechanisms of renal injury and stone formation. Urol Res. 2010; 38(1):7-15. https://doi.org/10.1007/s00240-009-0226-0.

33. van Ulsen P, Kuhn K, Prinz T, Legner H, Schmid P, Baumann C, Tommassen J. Identification of proteins of Neisseria meningitidis induced under iron-limiting conditions using the isobaric tandem mass tag (TMT) labeling approach. Proteomics. 2009;9(7):1771-81. https://doi.org/10.1002/pmic.200800642.

34. Rhodes DCJ. Human Tamm-Horsfall protein, a renal specific protein, serves as a cofactor in complement 3b degradation. PLoS One. 2017;12(7): e0181857. https://doi.org/10.1371/journal.pone.0181857.

35. Wu TH, Li KJ, Yu CL, Tsai CY. Tamm-Horsfall protein is a potent Immunomodulatory molecule and a disease biomarker in the urinary system. Molecules. 2018;23(1). https://doi.org/10.3390/molecules23010200.

36. Langdon A, Grohe B. The osteopontin-controlled switching of calcium oxalate monohydrate morphologies in artificial urine provides insights into 
the formation of papillary kidney stones. Colloids Surf B: Biointerfaces. 2016; 146:296-306. https://doi.org/10.1016/j.colsurfb.2016.06.030.

37. Xi Q, Ouyang J, Pu J, Hou J, Wang S. High concentration of calcium stimulates calcium oxalate crystal attachment to rat tubular epithelial NRK cells through Osteopontin. Urology. 2015;86(4):844 e841-5. https://doi.org/ 10.1016/j.urology.2015.07.018.

38. Ishii H, Baffa R, Numata Sl, Murakumo Y, Rattan S, Inoue H, Mori M, Fidanza $V$, Alder H, Croce CM. The FEZ1 gene at chromosome 8p22 encodes a leucine-zipper protein, and its expression is altered in multiple human tumors. Proc Natl Acad Sci U S A. 1999;96(7):3928-33. https://doi.org/10. 1073/pnas.96.7.3928.

39. Gao F, Huang W, Zhang Y, Tang S, Zheng L, Ma F, Wang Y, Tang H, Li X. Hes1 promotes cell proliferation and migration by activating Bmi-1 and PTEN/Akt/GSK3beta pathway in human colon cancer. Oncotarget. 2015; 6(36):38667-80. https://doi.org/10.18632/oncotarget.5484.

40. Kay SK, Harrington HA, Shepherd S, Brennan K, Dale T, Osborne JM, Gavaghan DJ, Byrne HM. The role of the Hes1 crosstalk hub in Notch-Wnt interactions of the intestinal crypt. PLoS Comput Biol. 2017;13(2):e1005400 https://doi.org/10.1371/journal.pcbi.1005400.

41. Tang DD, Gerlach BD. The roles and regulation of the actin cytoskeleton intermediate filaments and microtubules in smooth muscle cell migration. Respir Res. 2017;18(1):54. https://doi.org/10.1186/s12931-017-0544-7.

\section{Publisher's Note}

Springer Nature remains neutral with regard to jurisdictional claims in published maps and institutional affiliations.

Ready to submit your research? Choose BMC and benefit from:

- fast, convenient online submission

- thorough peer review by experienced researchers in your field

- rapid publication on acceptance

- support for research data, including large and complex data types

- gold Open Access which fosters wider collaboration and increased citations

- maximum visibility for your research: over $100 \mathrm{M}$ website views per year

At BMC, research is always in progress.

Learn more biomedcentral.com/submissions 